\title{
A educação online e os desafios à qualificação profissional em saúde
}

\author{
DOI: 10.3395/reciis.v4i5.393pt
}

\begin{abstract}
Josué Laguardia
Instituto de Comunicação e Informação Científica e Tecnológica em Saúde,Fundação Oswaldo Cruz (Icict/Fiocruz), Rio de Janeiro, Brasil jlaguardia@icict.fiocruz.br
\end{abstract}

\section{Angela Casanova}

Escola Politécnica de Saúde Joaquim Venâncio, Fundação Oswaldo Cruz (EPSJV/Fiocruz), Rio de Janeiro, Brasil angelacasanova@fiocruz.br

\begin{abstract}
Resumo
A disseminação dos recursos da web como ferramentas cognitivas na educação à distância têm fomentado a discussão acerca dos aspectos pedagógicos que sustentam as propostas educativas em ambientes virtuais, implicando em desafios a serem enfrentados pelos diversos atores inseridos nos novos contextos de aprendizagem on-line no âmbito da saúde. Tomando como pressupostos que a implementação e apropriação das tecnologias de informação e comunicação dependem da interrelação entre as características individuais, sociais e organizacionais, buscou-se nesse trabalho discutir alguns desafios pedagógicos subjacentes à concepção de ambientes virtuais de aprendizagem, bem como as especificidades de seus atores imersos em um processo interativo e interacional, apontando alguns fatores que influenciariam o sucesso das experiências de educação on-line para profissionais de saúde
\end{abstract}

Palavras-chave

educação on-line; tecnologias educativas; qualificação profissional em saúde.

\section{Introdução}

A ampliação das redes telemáticas, a disseminação dos computadores pessoais, o desenvolvimento da Internet, o aumento de banda para o acesso à rede global e a identificação da educação com a transmissão de saberes ao longo de toda a vida constituem, segundo Otto Peters (2004), o quarto período de evolução da Educação a Distância (EAD), sucedendo a educação por correspondência, o rádio/televisão e os CD-ROM interativos. A disponibilidade de recursos tecnológicos a um custo acessível, a disputa por nichos no mercado e a expectativa de ganhos por uma economia de escala servem como fatores motivadores para a implementação de cursos online em instituições de ensino (MA et al., 2000).

A educação online configura-se através da articulação dos dispositivos de formação a distância aos dispositivos de comunicação midiatizados (PERAYA, 2002) ancorados na arquitetura distribuída pela Internet e em padrões tecnológicos que favorecem a compatibilidade, a usabilidade e a interatividade. É a modalidade de educação a distância realizada via Internet exclusivamente, sem apoio de material didático impresso ou contato presencial (NICHOLS, 2003) e cuja comunicação pode ocorrer de forma sincrônica ou assincrônica (ALMEIDA, 2003). De acordo com Ally (2004), 
trata-se do "uso da internet para acessar materiais de aprendizagem, para interagir com o conteúdo, instrutor e outros estudantes e para obter apoio durante o processo de aprendizagem a fim de adquirir conhecimento, construir significado pessoal e crescer com a experiência educativa" (ALLY, 2004). Muitas vezes empregadas como sinônimos, a educação online diferencia-se do e-Learning, pois esta é definida como uma modalidade de educação a distância com suporte na Internet para formação continuada no setor empresarial (ALMEIDA, 2003) ou que utiliza uma rede (local area network, wide area network ou Internet) e respectivas ferramentas tecnológicas para os propósitos de educação profissional (LÖFSTED et al., 2001; NICHOLS, 2003).

Para Benigno e Trentin (2000), o caráter social da educação online é um fator que a distingue das gerações anteriores da $\mathrm{EAD}$, criando ambientes virtuais que promovem a comunicação interpessoal e a aprendizagem colaborativa. As vantagens atribuídas à educação online residiriam na ampliação do acesso à educação, na redução de custos, na adequação das atividades educativas ao tempo, ritmo e lugar mais convenientes aos alunos, na acomodação de estilos de aprendizagem individualizados e no fomento a uma atuação colaborativa, enquanto a falta de infraestrutura computacional, as dificuldades no acesso ao ambiente e aos conteúdos e a sensação de isolamento são apontadas como barreiras ao bom desempenho dos alunos nos ambientes virtuais de aprendizagem.

A organização e o acesso à educação online requerem sistemas de gerenciamento da aprendizagem (learning management system - LMS) que incluem controle de acesso, provisão do conteúdo, ferramentas de comunicação, organização de grupos de usuários e gerenciamento das atividades através de uma interface administrativa compartilhada. Por sua vez, os ambientes virtuais de aprendizagem (virtual learning environment - VLE) são sistemas computacionais (plataformas) residentes na Internet que dão suporte às atividades de aprendizagem mediadas pelas tecnologias de informação e comunicação e se caracterizam pela integração de múltiplas mídias e recursos, apresentação de informações de maneira organizada e disponibilidade de ferramentas inovadoras de interação/ colaboração. É importante ressaltar que o termo ambiente virtual de aprendizagem pode ser empregado para designar também os sistemas de gerenciamento da aprendizagem (Learning Management System - LMS), embora algumas definições de VLE enfoquem mais as condições de aprendizagem do que o seu gerenciamento, dado que, em determinadas circunstâncias, essas funções possam ser realizadas por aplicativos distintos na Internet.

A disseminação dos recursos da web como ferramentas cognitivas na educação a distância tem suscitado discussões acerca dos aspectos pedagógicos que sustentam as propostas educativas em ambientes virtuais e os papéis de alunos e professores, bem como os desafios à aprendizagem no contexto da educação online (OLIVER et al., 2002; HILL et al., 2003; McKIMM et al., 2003; STRUCHINER et al., 2006). Tomando como pressuposto que a implementação e apropriação das tecnologias de informação e comunicação na formação profissional dependem da inter-relação entre as características individuais, sociais, organizacionais e políticas, buscou-se neste artigo descrever alguns desafios pedagógicos subjacentes à concepção de ambientes virtuais de aprendizagem em cursos online de especialização em saúde, bem como as especificidades de seus atores imersos em um processo interativo e interacional, apontando um conjunto de fatores que influenciariam os resultados das experiências de educação online na saúde. Este artigo pretende fomentar uma discussão no contexto educacional brasileiro sobre as possibilidades e limitações da modalidade de educação online, principalmente considerando-se que, ao longo dos últimos anos, essa modalidade aumentou sua participação nas propostas de formação profissional em saúde no país (STRUCHINER et al., 2001).

\section{Aspectos pedagógicos e ambientes virtuais de aprendizagem}

Seja na modalidade presencial ou a distância, a relação professor-aluno pode ser caracterizada pela priorização, no processo pedagógico, da transmissão de conhecimentos/ conteúdos, estabelecidos numa relação hierárquica entre professor e aluno. Não obstante, um dos aspectos mais destacados acerca da educação a distância em ambientes virtuais de aprendizagem é o seu potencial para suscitar mudanças na concepção mais frequente que caracteriza o ensino presencial.

Na educação a distância, o docente, em geral, precisa assumir o papel de supervisão e apoio aos alunos, o que, por outro lado, requer a adoção de uma postura mais autônoma destes no processo ensino-aprendizagem. Assim, a depender do processo pedagógico implícito no curso, o docente é mobilizado a perceber o aluno como um estudante autodirecionado, ao mesmo tempo em que 
os conteúdos educacionais estariam caracterizados por serem mais suscetíveis a atualizações e disponíveis em diversos formatos, ao invés de homogêneos e estáveis (QUINTANA, 1996).

Na sala de aula virtual, a ênfase recai sobre os processos que os estudantes estabelecem entre si, com o tutor, com o material e com o próprio ambiente, na construção contínua do conhecimento. Essas mudanças demandam uma reflexão acerca das práticas educativas e sua relação com os fundamentos teóricos de aprendizagem, as concepções tecnológicas dos ambientes virtuais de aprendizagem e as atividades e dispositivos tecnológicos de comunicação e informação que apóiam os princípios e as teorias de aprendizagem subjacentes (DALSGAARD, 2005).

A educação, sob a ótica comportamentalista, é percebida como processamento de informação que provê uma comunicação eficiente de informações e estratégias efetivas para recordação dos conteúdos. Atribui-se importância às interações do aluno com o professor e o conteúdo, ao passo que as estratégias instrucionais focalizam o conteúdo pré-especificado, e o resultado do ensino baseia-se na avaliação orientada por metas e objetivos. O aluno recebe passivamente os conteúdos transmitidos pelo professor, que preside todas as etapas do processo ensino-aprendizagem e garante maior controle sobre a ação dos alunos.

A aprendizagem, dentro do modelo comportamentalista, consiste, primariamente, na modelagem de comportamentos desejáveis através de um ciclo: a provisão de um estímulo, na forma de uma apresentação breve do conteúdo, a demanda de uma resposta, na forma de uma pergunta, uma retroalimentação acerca da acurácia da resposta, o reforço positivo para respostas corretas ou a repetição do estímulo original ou de uma versão modificada dele para as respostas incorretas (CONOLE et al., 2004). A escola de aprendizagem comportamentalista vê a mente como uma caixa preta, no sentido de que a resposta ao estímulo pode ser observada quantitativamente, ignorando-se totalmente o efeito dos processos de pensamento que ocorrem na mente (ALLY, 2004).

Dentro dessa perspectiva, os ambientes virtuais de aprendizagem têm como objetivo garantir que o conteúdo apresentado ao aluno seja abrangente e preciso com respeito aos conhecimentos mais atuais, estabelecendo uma estrutura de saberes para um dado domínio e orientando as ações corretivas de modo a alcançar os resultados esperados da aprendizagem. Os materiais devem ser organizados de maneira sequencial, do mais simples ao mais complexo, do conhecido para o desconhecido, da apreensão teórica à aplicação prática e com unidades predeterminadas (currículo). As relações nesse ambiente de ensino caracterizam-se pela instrução do professor e o treinamento do aluno, regidas pelo conteúdo do curso e a avaliação do aluno. Essa proposta (abordagem) pedagógica nos remete às críticas empreendida por Paulo Freire $(1970,1998)$ à educação bancária: o caráter da narração nas relações entre educador e educandos, que se caracteriza pela existência de um sujeito - educadornarrador - e seus objetos, educandos-ouvintes.

Nessa relação, "o educador aparece como seu indiscutível agente, como o seu real sujeito, cuja tarefa indeclinável é "encher" os educandos dos conteúdos de sua narração. O autor ainda complementa sua crítica assinalando que "a narração de que o educador é sujeito, conduz os alunos à memorização mecânica do conteúdo narrado. Mais ainda, a narração os transforma em "vasilhas", em "recipientes" a serem enchidos pelo educador (FREIRE, 1970, 1998). Essa característica pode ser observada em cursos de formação profissional na modalidade de educação a distância, em cujo ambiente virtual de aprendizagem são depositados apostilas, livros e outros materiais para que os alunos façam o download e estudem os conteúdos estabelecidos, utilizando o ambiente virtual apenas para o envio de atividades e avaliações.

Por seu turno, a epistemologia construtivista assume que o conhecimento é fruto da construção adaptativa individual e da interação com o meio e que o entendimento é resultado de um engajamento ativo do aluno e de negociações entre o que é exterior e o que é interno a ele. Não existe conhecimento objetivo e absoluto. Ele é construído individualmente e subjetivamente, com base em experiências prévias e na reflexão metacognitiva.

A verdade no construtivismo é substituída pela viabilidade de ideias relativa a um contexto de metas e propósitos que não estão limitados ao concreto, ao material ou à solução de problemas específicos, mas amparados na construção de modelos mentais que são usados para explicar, predizer ou inferir fenômenos no mundo real (LEFOE, 1998; JONES et al., 2002). A filosofia pedagógica construtivista enfatiza as experiências, intenções e estratégias metacognitivas do aluno, o contexto e a solução de problemas concretos como elementos cruciais para a construção de significado associado ao conhecimento, e o professor é o mediador ou facilitador desse processo.

A aprendizagem pauta-se pelo estímulo à construção do conhecimento sob múltiplas perspectivas e modos de representação e na aquisição de asserções e estratégias viáveis que atendem aos objetivos individuais. Uma abordagem construtivista no desenho de um curso de EAD 
é dependente do modo como são traduzidas as metas de aprendizagem em atividades, assumindo que não há fases claramente distintas como no modelo comportamentalista, pois elas se sobrepõem e são contínuas.

Na definição do conteúdo, o professor pode selecionar um domínio principal do assunto sem limitar seu escopo em fronteiras arbitrárias, enfatizando a interação entre as estruturas cognitivas individuais e o ambiente por meio dos recursos interativos das tecnologias de informação e comunicação. Os objetivos da aprendizagem são concebidos como uma orientação para o uso dos objetos de aprendizagem, sem especificar, necessariamente, o que deverá ser aprendido.

Uma vez que a aprendizagem é considerada como o desenvolvimento com base nas experiências, ela deve enfocar as atividades que promovam o desenvolvimento individual de redes ou mapas mentais cognitivos mais apropriados. As estratégias de aprendizagem (mapas conceituais, perguntas) devem ser usadas para que o aluno recupere a informação existente com vistas à sua aplicação na vida real, contextualizando-a e facilitando seu processamento de modo a torná-la significativa. Os materiais online devem ser apresentados em diferentes formatos (texto, áudio, vídeo) e as atividades precisam contemplar os diferentes estilos de aprendizagem, possibilitando novas formas de discurso e de representação em comunicações que propiciem a reflexão.

Uma proposta que se caracteriza enquanto estratégia intermediária entre a abordagem centrada no professor e a centrada no aluno é a teoria conversacional (LAURILLARD, 2002), na qual o processo de aprendizagem envolve um intercâmbio interativo em dois níveis distintos. No primeiro, o professor apresenta o conhecimento conceitual, ideias ou teorias, e o aluno se familiariza com o conteúdo através de perguntas e respostas. No segundo, caracterizado pelas atividades interativas, o aluno coloca a teoria na prática através de tarefas experienciais - exercícios, experimentos laboratoriais ou viagens de campo. O professor acompanha o progresso experiencial dos estudantes, provê a retroalimentação e auxiliaos na compreensão dos conceitos, ao mesmo tempo em que os alunos refletem sobre suas experiências, estabelecendo uma ponte entre a teoria e a prática.

A interação é central nesse modelo educacional, e as conversações incluem não apenas trocas verbais, mas outros tipos de interações que envolvem autorreflexão e monitoramento da própria atividade de aprendizagem. É esperado que professores e alunos sejam responsivos e reativos às ideias e práticas dos outros, bem como às suas próprias práticas, e as mídias utilizadas devem facilitar as trocas conversacionais.
Todavia, se a aprendizagem é concebida como uma atividade predominantemente dialógica sociocultural, então o ensino deve prover oportunidades para incluí-la em tarefas autênticas que levem à participação em comunidades de prática. As comunidades de prática constituiriam, segundo Illera (2007), uma mudança de perspectiva na educação, ao estreitar a interligação entre conceitos anteriormente separados: aprendizagem, identidade, prática, significado, comunidade e contexto. Para esse autor, essas comunidades serviriam como elemento-chave na compreensão dos processos e mecanismos de influência educativa que ocorrem em contextos educativos não-formais, propiciando a união da experiência pessoal aos aspectos cognitivos, afetivos e sociais, situando a noção de aprendizagem em um contexto mais geral, o da própria vida das pessoas que aprendem, a despeito da sua pertença temporal a uma instituição educativa.

As comunidades virtuais de prática possibilitam o desenvolvimento de atividades educativas ancoradas na aprendizagem socialmente situada, tendo como base quatro premissas: a aprendizagem está ancorada nas ações das situações cotidianas; o conhecimento é adquirido situacionalmente e transferido apenas em circunstâncias similares; a aprendizagem é o resultado de um processo social relativo ao modo de pensar, perceber, solucionar problemas e interagir, bem como ao conhecimento explícito; a aprendizagem não está separada do mundo da ação, mas inserida em ambientes sociais complexos constituídos de atores, ações e situações.

As comunidades de prática, outrossim, possibilitam que cognição e conhecimento construam-se na rede de relações e atividades de participação. De acordo com Dias (2007), "a cognição e o conhecimento no modelo da participação não estão localizados no indivíduo, mas na rede de relações e actividades de participação que formam a comunidade e promovem o desenvolvimento da representação distribuída. Na perspectiva da metáfora da participação, os aspectos culturais, sociais e contextuais das aprendizagens são o suporte para a cognição situada e distribuída, cuja expressão são as comunidades de prática".

O modelo de cognição situada, marco teórico da aprendizagem socialmente situada, se apóia precisamente nas interações sociais e na linguagem como ferramenta comunicacional e cultural para o desenvolvimento do conhecimento compartilhado e como ferramenta psicológica para a organização dos pensamentos individuais (DABBAGH, 2005). Esse modelo destaca a importância das múltiplas formas de comunicação e requer ambientes de aprendizagem 
ricos em interação e diálogo. A aprendizagem deverá ser concebida como um processo ativo com atividades significativas, de caráter colaborativo e cooperativo, sob controle do aluno e predominantemente interativa, criando um sentido de presença e de comunidade e promovendo a aprendizagem transformacional. Desse modo, o processo educativo online deve propiciar situações de aprendizagem que incentivem a negociação de significados dos conteúdos pelo aprendiz sob múltiplas perspectivas, desenvolver atividades que facilitem a interação entre os participantes, fornecer materiais de apoio e fomentar a atuação do professor como mediador e orientador do aluno.

\section{Interação e interatividade em ambientes virtuais de aprendizagem}

Um aspecto a ser destacado nos ambientes virtuais de aprendizagem é o seu potencial para colaboração e negociação através de ferramentas interativas. Belloni (2003) define a interação como ação recíproca entre dois ou mais atores, cuja intersubjetividade pode ser direta ou indireta e midiatizada por ferramentas de comunicação. A interação se diferenciaria da interatividade porque esta se refere tanto à potencialidade técnica oferecida por determinado meio (CDROM, jogos e hipertextos) quanto à ação do usuário sobre a máquina e a retroação da máquina sobre ele. Nichols (2003) classifica a interatividade em dois tipos: indicativa, tipificada pelo uso de botões de navegação e rolagem; e simulativa, que capacita os estudantes a aprender em uma situação de simulação, a partir de suas próprias escolhas e provendo-os com alguma forma de retroalimentação. Essas atividades de interação midiatizada e de interatividade criadas pelas redes telemáticas (e-mails, chats, grupos e listas de discussão, websites) ocorrem em tempo real (imediata ou síncrona - com horário fixo e prestabelecido) ou não (mediata ou assíncrona - maior flexibilidade de horário) e mesclam características da linguagem oral e escrita (TESTA, 2001).

No tocante à teoria comunicacional, Primo (2005) refere quatro enfoques possíveis no estudo da interação mediada por tecnologias de informação e comunicação: o enfoque transmissionista faz referência à bidirecionalidade e considera os fluxos de emissão e recebimento; no enfoque informacional, os elementos, como ação-reação (frequência), seleção entre alternativas disponíveis (amplitude) e o impacto das escolhas (significância), por mais numerosas que sejam as opções possíveis, estariam sob controle do desenvolvedor; o enfoque tecnicista mede o potencial do meio em permitir ao usuário escolher o fluxo de informações que deseja receber (interatividade de transmissão), solicitar informações em um sistema com canal de retorno (interatividade de consulta), produzir e enviar suas próprias informações (interatividade de conversação) e, ainda, registrar as informações dos usuários e responder a suas necessidades e ações (interatividade de registro) - esse enfoque caracterizase por enfatizar o potencial técnico dos meios e não a relação entre os interagentes; por fim, o enfoque sistêmicorelacional caracteriza-se pelo encadeamento dos atos comunicativos pautados nos aspectos de conteúdo, relação e na interdependência dos relacionamentos na interação para construção do conhecimento. Nesse caso, o conhecimento não é concebido como objeto, mas como ação, movimento, redes, conexões.

Para esse autor, dentre as possibilidades de interação mútua, destacam-se a problematização, a negociação e as modificações recíprocas dos interagentes durante o processo interacional (recursão). Por outro lado, dentro do que denomina ser uma interação reativa, destaca-se a previsibilidade e automatização nas trocas (input/output).

A interação em ambientes virtuais de aprendizagem, segundo Vrasidas (2000), pode ocorrer entre aluno-professor, aluno-conteúdo, aluno-aluno e aluno-interface. A interação aluno-conteúdo é uma característica definidora da educação e corresponde ao começo do processo de construção do conhecimento pela acomodação da informação em estruturas cognitivas pré-existentes. A Internet provê novas oportunidades de interação aluno-conteúdo e aluno-interface, por meio de imersão em microambientes, exercícios em laboratórios virtuais e tutoriais online com retroalimentação imediata. A interação aluno-professor é considerada essencial e altamente falta algo aqui ao estimular o interesse dos alunos pelo conteúdo e ao motivá-los a aprender, com reflexos positivos na taxa de conclusão dos cursos online.

A interação entre o professor e o aluno nos ambientes virtuais de aprendizagem ocorre de modo simultâneo ou diferido, de acordo com as tecnologias de interatividade (e-mails, mensagens e chat) empregadas nos processos de comunicação. As modernas tecnologias de comunicação disponíveis nos ambientes virtuais de aprendizagem podem favorecer diversas formas de interação entre alunos e professores: seja entre aluno-aluno, um aluno e os demais, ou no contexto de grupo, com ou sem a presença, em tempo real, do professor. Essas diversas possibilidades de interação favorecem a aprendizagem colaborativa e que os alunos comparem sua compreensão dos conceitos sob estudo com a dos seus colegas (TIMMS et al., 1999). Há também 
a interação professor-professor, que cria oportunidades de apoio e desenvolvimento profissional, bem como a interação professor-conteúdo, que garante a atualização e o monitoramento contínuo dos recursos de conteúdo e das atividades desenvolvidas para a aprendizagem do aluno (ANDERSON, 2004).

Os ambientes virtuais de aprendizagem apresentam a vantagem de combinar interações individuais e grupais de forma integrada, mútua, flexível e independente no tempo e no espaço, possibilitando a exploração de novos conhecimentos, a convivência virtual e a constituição de comunidades de aprendizes. Na perspectiva do construtivismo sociocultural, a interação social eletrônica cria, utiliza e estende zonas de desenvolvimento proximal para fomentar as habilidades e capacidades do aluno que estavam originalmente ativas apenas em situaç̃oes de aprendizagem colaborativa ou assistida, mas que, gradualmente, tornam-se internalizadas como processos auto-regulatórios independentes.

Além da interação, outros aspectos positivos estão relacionados à educação online, tais como a economia de tempo e de custos em decorrência da reutilização de materiais empregados em outros cursos e da ausência de deslocamento físico dos professores e alunos para participação nas aulas, bem como maior acesso à informação qualificada, flexibilidade no estudo (qualquer hora e lugar), anonimato e o reconhecimento institucional pela adoção de tecnologias inovadoras.

\section{O papel do tutor e do aluno nos ambientes virtuais de aprendizagem}

A principal tarefa do tutor nos ambientes virtuais, de acordo com Peters (2004), é desenvolver sistemas de aprendizagem não-lineares em hipertexto/hipermídia, expressando a complexidade da aprendizagem acadêmica e apoiando-a por exploração e descoberta. Ao tutor também são atribuídos os papéis de anfitrião, leitor, facilitador, mediador, provocador e organizador de uma comunidade. Maudsley (1999) assinala que o tutor é um guardião dos processos do grupo e um guia para a descoberta, ao invés de um modelo perfeito de dispensador de informações ou um empolgado líder de torcida. Na mediação pedagógica, o professor-tutor estimula o aluno a assumir sua condição de sujeito do processo de aprendizagem, desafiando-o e motivando-o na busca de respostas adequadas às atividades propostas (LOSSO, 2002). Dentre os requisitos esperados desses profissionais, está o uso de vários métodos educativos, desenvolvimento de habilidades de questionamento, de pesquisa e de escrita, o conhecimento do contexto onde se dá o trabalho dos participantes, a exposição das ideias de modo claro e o estabelecimento de um clima de interação apropriado.

As competências pessoais do tutor estariam relacionadas ao desejo de ensinar, o respeito ao aluno, motivando-o por meio de uma comunicação efetiva. Ele é um parceiro dos seus alunos, que identifica as suas representações de pensamento, compartilha informações relevantes, incentiva a busca por diferentes fontes de estudo e pesquisa, provoca a reflexão sobre os processos e seus produtos, favorecendo a formalização de conceitos e propiciando o estabelecimento de múltiplas e mútuas relações e recursões. Nos ambientes virtuais de aprendizagem, é requerido dos tutores o desenvolvimento de habilidades para o gerenciamento das interações (KING, 2002) que fomentem um sentimento de engajamento, competências relacionadas aos usos apropriados dos recursos tecnológicos de comunicação e a orientação dos alunos na solução dos problemas técnicos.

Aos alunos adultos, são atribuídas necessidades de aprendizagem vinculadas aos papéis sociais cambiantes, com aplicação imediata do conhecimento adquirido e valorização das suas experiências de vida como recurso na aprendizagem (CONLAN et al., 2003). Na literatura da educação online, os alunos são percebidos como autônomos, autodirigidos, motivados por fatores internos, disciplinados, comprometidos, capazes de organizar o seu tempo para o desempenho das atividades educativas, de se expressar de maneira clara e sucinta e dispor de habilidades para o trabalho independente. Como aponta Fiúza (2002), se a motivação é um componente individual e interno com reflexos no desempenho do aluno nos cursos a distância, a única ação para mantê-los motivados é conhecer as suas características socioculturais, conhecimentos, experiências, demandas e expectativas e oferecer atividades de aprendizagem que satisfaçam essas necessidades.

Ao assumirem a maioria das funções comumente designadas aos professores, os estudantes, nos ambientes virtuais de aprendizagem, são incentivados a desenvolver as habilidades de autodeterminação, orientação, seleção, capacidade de tomar decisões, de aprender e organizar, criando um comportamento de aprendizagem estruturalmente diferente daquele exibido no ensino superior tradicional. O ambiente virtual permite um nível de engajamento e empoderamento dos estudantes que é mais difícil de encontrar em uma sala de aula tradicional (NULDEN, 2001). $\mathrm{O}$ uso de ambientes virtuais numa perspectiva de interação 
e construção colaborativa de conhecimento favorece as trocas individuais, o desenvolvimento de competências de trabalho em grupo e de habilidades relacionadas com a escrita. A participação em um ambiente virtual e colaborativo de aprendizagem significa mergulhar em um mundo cuja comunicação se dá essencialmente pela leitura e interpretação de materiais didáticos textuais e hipertextuais, e expressão do pensamento através da escrita (CARVALHO et al., 2001).

\section{Os desafios à aprendizagem em ambientes virtuais}

A aprendizagem em ambientes virtuais requer uma coerência entre a proposta pedagógica do curso, as características do aluno e a ação do tutor, exigindo-lhes a capacidade de explorar os recursos educativos e tecnológicos disponíveis. Em um ambiente virtual, a configuração de um curso sob os preceitos da proposta pedagógica comportamentalista, característica comum em cursos presenciais que migram para a modalidade online, pode limitar os papéis dos tutores e alunos aos de provedor e receptor da informação, exigindo-se desses últimos o cumprimento das tarefas e atendimento às atividades programadas. A demanda por ferramentas de comunicação restringe-se, na maioria das vezes, ao uso de correio eletrônico para envio dos trabalhos e solução de dúvidas do aluno pelo tutor.

A opção por uma abordagem interacionista pressupõe a constituição de ambientes virtuais com conteúdos relevantes e significativos para o aluno, que facilitem a interação entre os participantes do curso e cujos tutores apóiem os alunos, estimulando-os a uma participação ativa e colaborativa nos processos de aprendizagem. Isso requer o uso de recursos que possibilitam a interação e o compartilhamento de conhecimentos, dentro de uma proposta de aprendizagem colaborativa, tais como fórum de discussão, sala de batepapo, videoconferência, blog, wiki, criação de comunidades virtuais e simuladores em três dimensões.

Enquanto para alguns alunos o anonimato e a diminuição das distinções de status, produzidas pelo uso de comunicações mediadas por computador, podem servir de incentivo à criatividade, participação mais igualitária nas decisões e à percepção de maior visibilidade, para outros essas características geram insatisfação, lentidão no desenvolvimento de vínculos relacionais e perda da motivação (VALCKE et al., 2004). Esse sentimento de isolamento provocado pela experiência da educação online pode ser atenuado pela incorporação de tecnologias de comunicação síncrona, como chat, whiteboard, áudio e videoconferência, além de reduzir o uso da escrita às atividades de cunho avaliativo. Entretanto, o uso dessas tecnologias exige a presença simultânea dos participantes, a constituição de grupos pequenos, pela dificuldade em seguir as diferentes 'conversas' que se vão desenrolando, e a disponibilidade de equipamentos, aplicativos e banda de transmissão que podem implicar em custos operacionais mais elevados e ônus ao aluno na aquisição ou adequação dos recursos computacionais disponíveis.

A escrita, que constitui um elemento central no processo avaliativo de alunos em cursos online, representa um desafio importante para os tutores, desde a diferenciação entre um aluno com baixa proficiência escrita daquele com pouca preparação ou engajamento no curso até a exigência de habilidades de escrita e a necessidade de que os seus comentários e indicações sejam entendidos de maneira clara pelos alunos (LIANG et al., 2004). Quanto aos alunos, além da capacidade de se expressar de maneira objetiva e crítica nas avaliações escritas e nas mensagens postadas nos fóruns de discussão, há também a questão da autenticidade de autoria dos trabalhos

O plágio, um dos componentes da desonestidade acadêmica, caracteriza-se como o evento onde uma pessoa apresenta um trabalho de outra pessoa, intencionalmente ou não, como sendo dela, com a finalidade de obter algum benefício (HART et al., 2004). O plágio pode variar desde a não atribuição de fontes por falta de conhecimento das convenções, a escrita por colagem até uma fraude. Embora não seja exclusivo aos ambientes virtuais de aprendizagem, as características da educação a distância e as facilidades propiciadas pela Internet parecem tê-lo favorecido. As soluções apontadas, tais como a exigência de comprovação de algumas referências citadas no trabalho por meio da solicitação de fotocópias dos artigos, o ensino de técnicas de redação de trabalhos científicos, o reforço das convenções acadêmicas, a orientação para o gerenciamento do tempo e a redução do número de tarefas, embora alertem o aluno sobre a preocupação da instituição acerca dessa prática, não garantem a sua diminuição. Uma discussão mais aprofundada sobre a definição de autoria é requerida à medida que novas experiências de aprendizagem colaborativa são implementadas na educação online.

No que concerne ao tutor, a aquisição de competências para o manejo dos recursos comunicacionais e tecnológicos se dá pela combinação de experiências prévias, orientações formalizadas em manuais, relatos de avaliações formais e informais das práticas adotadas ao longo do curso que sugerem quais estratégias são mais adequadas em diferentes situações de aprendizagem. Entretanto, tais competências 
podem estar limitadas pelas características dos tutores e dos alunos, pois a igualdade no alcance de habilidades e os benefícios provenientes das propostas pedagógicas inovadoras e das novas tecnologias de informação e comunicação não é algo que possa ser assumido para todos os participantes. Dentro de um mesmo ambiente de educação online, podem ser encontrados diferentes estilos de tutoria e identidades de aluno, dependentes do modo como tutor e aluno manejem os recursos pedagógicos e tecnológicos disponíveis para os objetivos da aprendizagem. Todavia, esses papéis não são necessariamente condicionados pela proposta pedagógica do curso, podendo ser constituídos seja na interrelação entre experiências prévias e atuais ou conformados por características psicológicas.

No ambiente online, Hughes e Lewis (2002) identificaram três identidades de alunos: o modelo, que é empreendedor, assume riscos, explora novas maneiras e desfruta dos benefícios dos ambientes virtuais de aprendizagem; o desencantado, que reconhece os benefícios das novas tecnologias, mas está insatisfeito com os resultados obtidos com o seu uso e, portanto, lança mão dos métodos de aprendizagem que the são mais familiares; o mal-adaptado, para o qual falta uma compreensão das novas pedagogias online e cujas expectativas de aprendizagem comprometem seu desempenho acadêmico, tornando-o resistente às novas tecnologias. A despeito das críticas à visão comportamental subjacente à definição dessas identidades, nota-se que a atitude do aluno em um curso online pode variar ao longo de um contínuo que se estende desde o tipo modelar ao desencantado/mal-adaptado, devido a mudanças no trabalho, problemas familiares, dificuldades técnicas ou qualquer outro evento que afete o tempo disponível ou a motivação em relação ao curso.

Na avaliação da experiência de alunos em um curso de aperfeiçoamento online, Laguardia et al. (2010) observaram que um conjunto desses alunos caracterizava-se por trabalhar em tempo parcial ou integral, ter disponibilidade limitada de tempo para estudar, dificuldades para atender às exigências da aprendizagem autônoma e ter por hábito, na maioria das vezes, a aprendizagem passiva. Ademais, a possibilidade de estudo no próprio ambiente de trabalho, de modo geral, conflitava com as demandas do trabalho, carência de insumos adequados para o acesso aos materiais educativos e com a falta de apoio efetivo dos gestores, ainda atrelados ao modelo de formação tradicional, que dissocia o local de estudo do espaço do trabalho. Esses autores discutem ainda que a liberdade e a flexibilidade presentes nos ambientes virtuais, a autonomia do aluno e a demanda por uma reflexão crítica dos conhecimentos apresentados no curso podem ser percebidas como fatores negativos à aprendizagem por alunos acostumados a serem orientados sobre quais e como devem ser feitas as atividades. Desse modo, assim como o tutor, o aluno precisa se deslocar do enfoque técnico e empiricista do conhecimento para uma prática pedagógica e crítica epistemológica de cunho construtivista. Esse deslocamento se mostra mais relevante entre os profissionais de saúde, cuja formação tem tradicionalmente se baseado em "métodos de ensino reprodutivistas que estimulam a passividade, a adoção de estratégias de estudo superficiais e uma aceitação acrítica do saber técnico" (ARAÚJO et al., 2007).

O processo de avaliação dos alunos na educação a distância, a despeito dos pressupostos construtivistas que fundamentam a concepção de muitos deles, ainda baseia-se na mensuração por meio de testes e exames do conhecimento transmitido. Os fóruns de discussão e os portifólios, diários e mapas conceituais caracterizam-se como ferramentas cognitivas que propiciam a aprendizagem reflexiva e metacognitiva de professores e alunos e constituiriam alternativas ao modelo tradicional, normativo e linear de avaliação (LAGUARDIA, 2007). Mas isso implica na participação efetiva de todos os alunos, excluindo da avaliação aqueles que apenas leem as mensagens ou que não se sentem motivados a participar. A participação compulsória, a definição do escopo da discussão e a restrição temporal dos fóruns podem levar à ausência física ou mental do aluno, que posta mensagens não-engajadas apenas para atender às exigências do curso. Não se deve descartar a possibilidade de a ausência de participação ser compensada pelo envolvimento do aluno em outras atividades do curso igualmente relevantes à sua aprendizagem.

Quanto à definição dos critérios de avaliação da participação dos alunos nos fóruns de discussão, esta fica, na maioria das vezes, a cargo do tutor, que pode ser auxiliado nessa tarefa com regras mais explícitas, tais como a adoção de taxonomias validadas, tais como as taxonomias cognitivas de Bloom (FERRAZ et al., 2010) e a SOLO de Biggs (LAGUARDIA et al., 2009). A utilização dessas taxonomias pode servir à avaliação pelos tutores, a partir da definição prévia dos objetivos cognitivos esperados dos alunos, de quais processos cognitivos foram empregados por eles durante a aprendizagem e, consequentemente, quais as estratégias a serem revistas e modificadas nos cursos futuros.

Os atributos da mídia e o controle do aluno, medido pelo grau no qual ele é livre para fazer escolhas dentro de uma proposta pedagógica, a posse de habilidades e competências para se engajar nas experiências educacionais e a disponibilidade de recursos de apoio que o capacitem 
a participar de maneira efetiva influenciam a aprendizagem nos ambientes online. De acordo com Bonk \& Cunningham (1998), a tecnologia afeta a natureza e as metas do processo de aprendizagem, ao dispor de ferramentas educacionais colaborativas que fomentam emoções e cognições, incluindo a tensão do debate com outros estudantes e a busca compartilhada por novos conhecimentos. Nesse sentido, a opção por aplicativos de código aberto para gerenciamento de conteúdos e atividades na educação online, além de eliminar os custos de aquisição e atualização de softwares, possibilita um papel mais criativo e proativo dos participantes na construção coletiva dos conteúdos e das estratégias interativas.

Todavia, os ambientes virtuais de aprendizagem não são inerentemente interacionais. Eles dependem da participação ativa dos estudantes e tutores por meio da frequência, da contribuição oportuna e da natureza das mensagens que são postadas, assim como das técnicas pedagógicas utilizadas. Ademais, a oportunidade do retorno dos comentários do tutor ao aluno acerca das suas atividades, a implementação de rotinas de autoavaliação, a habilidade de vincular recursos didáticos em diferentes formatos, o acesso aos materiais de maneira eficiente e rápida, o encorajamento para uma aprendizagem ativa e independente são alguns dos fatores do sucesso da aprendizagem em ambientes online (LAGUARDIA et al., 2010).

Face à emergência de novos instrumentos tecnológicos e de práticas de aprendizagem centradas no aluno, a maioria dos professores ainda se ressente da falta de apoio e direção no uso de tecnologias colaborativas dentro da perspectiva centrada no aluno, assim como a subestimação da carga de trabalho gerada pela atenção individualizada às demandas dos alunos (SCHRUM et al., 2002; BARBOSA et al., 2006). É esperado que os tutores disponham de conhecimentos específicos sobre os temas abordados na aprendizagem e de recursos pedagógicos que possibilitem uma atuação adequada e efetiva em um ambiente virtual de aprendizagem.

\section{A educação a distância na qualificação profissional em saúde}

Diversas experiências de qualificação profissional em saúde a distância vêm sendo desenvolvidas no país, favorecidas pelos investimentos do governo federal para ampliação da oferta de cursos nessa modalidade de ensino, com a prerrogativa de ampliar as oportunidades de acesso à formação profissional, com vistas ao fortalecimento do Sistema Único de Saúde.
Ao mesmo tempo, a consolidação da educação a distância no país teve um grande impulso a partir de investimentos oriundos do Ministério da Educação, no âmbito da criação da Universidade Aberta do Brasil, em 2005. Trata-se de um sistema composto por instituições de ensino com vistas a ofertar cursos de nível superior para grupos populacionais em situação de desigualdade no que se refere ao acesso à formação universitária. Ainda que sua prioridade seja a formação de professores que atuem na educação básica, cursos de qualificação profissional em saúde têm sido ofertados na UAB tanto aos profissionais do setor educação quanto aos do setor saúde, dentre os quais encontram-se bacharelados, licenciaturas, tecnólogos e especializações (pós-graduação), além de cursos voltados para o uso de tecnologias de informação e comunicação (mídias) na Educação e aqueles voltados à administração pública, com vistas à formação de gestores. No que se refere à temática da saúde, cursos de gestão em saúde, saúde da família, saúde indígena, educação ambiental e informática em saúde, vigilância sanitária, educação permanente em saúde e gestão de projetos de investimentos em saúde vêm sendo ofertados, por distintas instituições de ensino, como universidades (UFF, Unifesp, UFMG) e instituições de ensino e pesquisa (Fiocruz). Outro aporte de investimentos consideráveis para a qualificação de profissionais de saúde adveio da criação da UnA-SUS (Universidade Aberta do SUS) que, instituída em 2008, é resultante da ação conjunta do MS e OPAS-OMS, com vistas à criação de uma rede colaborativa de instituições acadêmicas e serviços de saúde para atender às necessidades de formação e educação permanente do SUS.

Esse cenário impõe a necessidade de estudos para avaliar o impacto e a efetividade desses cursos na formação de profissionais em saúde que irão atuar em uma diversidade de situações. Por seu turno, o acesso a equipamento e infraestrutura apropriados, a familiaridade com as novas tecnologias de informação e comunicação, o apoio pedagógico e de conteúdo aos tutores por profissionais qualificados, a integração e adequação da proposta pedagógica às demandas e condições laborais dos alunos e o acesso aos materiais educacionais após o término do curso estão relacionados ao êxito na formação profissional e devem ser considerados na concepção de cursos a distância no setor saúde mediados pela tecnologia (GRAFF, 2003; ALLY, 2004).

Alguns desafios enfrentados na educação a distância para a formação de profissionais de saúde estão relacionados a sua capacidade de oferecer um ambiente virtual de aprendizagem, dinâmico e interativo, com possibilidade de reprodução em CD Room, reconhecendo a diversidade de acesso à Internet ainda existente em nosso país, o apoio e 
orientação pedagógicos aos tutores, com vistas a auxiliá-los frente às dificuldades que os alunos apresentam no estudo a distância, encontros com orientadores de aprendizagem e com formuladores do curso (professores conteudistas) com o objetivo de garantir a qualificação contínua desses tutores nos conteúdos abordados e melhorar seu desempenho junto aos alunos. Outras possibilidades são disponibiliar material didático impresso e em mídia digital, a fim de favorecer a interatividade do aluno com o ambiente virtual, ao mesmo tempo em que não o limita a ter que permanecer online durante todo o tempo de estudo. E buscar integrar nas atividades de avaliação as atividades teóricas à vivência profissional dos alunos, favorecendo a aprendizagem significativa.

Um aspecto a ser destacado é que a implementação de cursos online pode representar custos mais elevados do que os cursos presenciais, em decorrência da adoção de enfoques e atividades pedagógicas que requerem requisitos computacionais mais elaborados (jogos, simulação, base de dados hipermídia) que podem estar disponíveis nos aplicativos de código aberto ou não, exigindo sua aquisição em separado, da contratação de profissionais para o desenvolvimento dos conteúdos, o delineamento das atividades curriculares e sua adequação aos ambientes virtuais, do pagamento de atividades de supervisão/orientação de aprendizagem, tutoria, monitoria e apoio técnico-administrativo, bem como da aquisição de equipamentos e mudanças na infraestrutura física das instituições promotoras desses cursos. Por outro lado, considerando-se as desigualdades regionais, do ponto de vista socioeconômico, as diferenças locorregionais em nosso país, no que se refere ao perfil de saúde - doença e prestação de cuidado da população -, a modalidade de educação a distância pode constituir dispositivo/estratégia importantes para a qualificação de trabalhadores com vistas ao fortalecimento do sistema único de saúde e a concretização de seus princípios doutrinários. No caso dos profissionais da educação básica, por exemplo, a EAD possibilita que mais elementos sejam incorporados aos currículos, de modo a expandir entre jovens e adultos a perspectiva da saúde como direito de cidadania, ampliando a participação popular e o controle social.

\section{Conclusão}

Nichols (2003) ressalta que não basta tornar disponíveis as ferramentas de educação online sem que estejam claros quais são seus benefícios reais e como integrá-los à proposta pedagógica de um curso. A escolha das ferramentas deve refletir mais do que determinar essa proposta, tendo como regra geral que o modo de uso é mais importante do que o tipo de tecnologia a ser empregada em um programa de educação online. Ademais, é importante conhecer as abordagens e condições de estudo dos alunos, pois uma prática efetiva de educação online depende de como os usuários se engajarão nas oportunidades de aprendizagem que lhe são providas e os efeitos positivos e negativos que essas experiências terão no desempenho do aluno ao longo do curso. O sucesso dos cursos em ambientes virtuais não reside exclusivamente no uso de uma tecnologia mais funcional ou aprimorada, embora essa ofereça oportunidades para o desenvolvimento de pedagogias inovadoras, mas na formação e valorização profissional dos professores-tutores, na compreensão das especificidades dos alunos e das particularidades do contexto em que se insere a proposta de formação.

$\mathrm{Na}$ discussão da interface com a educação, devese ter claro que o papel das tecnologias de informação e comunicação é o de criar um ambiente que facilite a aprendizagem (IMEL, 2001) e sua influência depende de mudanças significativas nos processos de aprendizagem e na compreensão das finalidades, razões e indicações do seu uso na educação. Contudo, essa discussão deve ter em conta a reestruturação do processo produtivo e suas repercussões no gerenciamento do saber, em que a propagada flexibilidade da aprendizagem em ambientes virtuais para formação de competências está inserida em um processo mais amplo de mudanças no sistema de poder das instituições.

As novas tecnologias de comunicação e informação e suas configurações no contexto da Internet não podem ser tomadas como algo dado, ou seja, que basta lançar mão desses recursos para que ocorram mudanças radicais na sociedade, na educação e na saúde. É preciso também situar a reflexão sobre a sociedade da informação/conhecimento dentro de marcos teóricos escolhidos para entender o que chamamos de cibercultura/cibersociedade e como a educação está colocada nesse novo paradigma.

A tão festejada flexibilidade da educação em ambientes virtuais de aprendizagem é algo que nos torna mais senhores do processo de conhecimento ou simplesmente repete velhos modelos comportamentalistas revestidos de novas roupagens e inscritos em uma modernização conservadora? A resposta a essa questão pode ser buscada na avaliação das experiências de educação online, que nos apontará as limitações situacionais, institucionais ou individuais a serem superadas, tanto no acesso e uso das novas tecnologias quanto na sua agregação a estratégias pedagógicas inovadoras. 


\section{Referências}

ALLY, M. Foundations of educational theory for online learning. In: ANDERSON, T.; ELLOUNI, F. (Eds.). Theory and pratice of online learning. Athabasca: Athabasca University, 2004. p.3-31.

ALMEIDA, M.E.B. Educação a distância na internet: abordagem e contribuições dos ambientes digitais de aprendizado. Educação e Pesquisa, v.29, n.2, p.327-340, 2003.

ANDERSON, T. Toward a theory of online learning. In: ANDERSON, T.; ELLOUNI, F. (Eds.). Theory and pratice of online learning. Athabasca: Athabasca University, 2004. p.33-60.

ARAÚJO, D.; MIRANDA, M.C.G.; BRASIL, S.L. Formação de profissionais de saúde na perspectiva da integralidade. Revista Baiana de Saúde Pública. v.31, n.1, p.20-31, 2007. Suplemento.

BARBOSA, M.F.S.O.; RESENDE, F. A prática dos tutores em um programa de formação pedagógica a distância: avanços e desafios. Interface - Comunicação, Saúde, Educação, v.10, n.20, p.473-486, 2006.

BELLONI, M. L. Educação a distância. Campinas: Autores Associados, 2003.

BENIGNO, V., TRENTIN, G. The evaluation of online courses. Journal of Computer Assisted Learning, v.16, p 259-270, 2000.

BONK, J.C., CUNNINGHAM, D.J. Searching for learnercentered, constructivist, and socio-cultural components of collaborative educational learning tools. In: BONK, C.J.; KING, K.S. (Eds.). Electronic collaborators: learner-centered technologies for literacy, apprenticeship, and discourse. Mahwah, NJ: Lawrence Erlbaum Associates Publishers, 1998. p.25-50.

CARVALHO, N.M., MISOSOCZKY, M.C.A. Potencialidades da aprendizagem virtual: uma reflexão a partir da experiência do curso de planejamento estratégico em saúde. In: MISOCZKY, M.C. A.; CARVALHO, N.M.; OLIVO, V. (Orgs.). Educação a distância: reflexões críticas e experiências em saúde. Porto Alegre: Dacasa, 2001. p.65-83.

CONLAN, J.; GRABOWSKI, S.; SMITH, K. Current trends in adult education. In: OREY, M. (Ed.). Emerging perspectives on learning, teaching and technology, 2003. Disponível em: <http://www.coe.uga.edu/epitt/AdultEducation.htm>. Acesso em: 13 maio 2005.

CONOLE, G. et al. Mapping pedagogy and tools for effective learning design. Computers \& Education, v.43, p.7-33, 2004.
COX, A. What are communities of practice? a comparative review of four seminal works. Journal of Information Science, v.31, n.6, p.527-540, 2005.

CULLEN, J. et al. Review of current pedagogic research and practice in the fields of post-compulsory education and lifelong learning. Final report. London: Tavistock Institute, 2002.

DABBAAGH, N. Pedagogical models for e-learning: a theory-based design framework. International Journal of Technology in Teaching and Learning, v.1, n.1, p.25-44, 2005.

DALSGAARD, C. Pedagogical quality in e-learning: designing e-learning from a learning theoretical approach. E-learning and Education (eleed) Journal, n. 1, Feb., 2005.

DIAS, P. Contextos de aprendizagem e mediação colaborativa. Repositório e-learning Open Educational Resources. Disponível em: <https://e- repository.tecminho.uminho. pt/handle/10188/65>. Acesso em: 8 dez. 2010.

FERRAZ, A.P.C.M.; BELHOT, R.V. Taxonomia de bloom: revisão teórica e apresentação das adequações do instrumento para definição de objetivos instrucionais. Gestão e Produção, São Carlos, v.17, n.2, p.421-431, 2010.

FICHANT, M. A epistemologia em França. In: CHÂTELET, F. História da filosofia: o século XX. Lisboa: Publicações Dom Quixote, 1995. p.113-140.

FIÚZA, P.J. Aspectos motivacionais na educação a distância: análise estratégica e dimensionamento de ações. 2002. 119f. Dissertação (Mestrado em Engenharia de Produção e Sistemas) - Universidade Federal de Santa Catarina, Florianópolis, 2002.

FREIRE, P. Educação "bancária" e educação libertadora. In: FREIRE, P. Pedagogia do Oprimido. Rio de Janeiro: Paz e Terra, 1970. p.65-87. Republicado em: PATTO, M.H.S. (Org.). Introdução à psicologia escolar. São Paulo: Casa do Psicólogo, 1998. p.61-78.

GARCIA, R. Planteo constructivista del problema del conocimiento. In: El conocimiento en construcción: de las formulaciones de Jean Piaget a la teoria de sistemas complejos. Barcelona: Gedisa Editorial, 2000. p.39-63.

GRAFF, M. Cognitive style and attitudes towards using online learning and assessment methods. Electronic Journal of e-Learning, v.1, n.1, p.21-28, 2003.

HART, M., FRIESNER, T. Plagiarism and poor academic practice: a threat to the extension of e-Learning in Higher Education? Eletronic Journal on e-Learning, v.2, n.1, p.89-96, 2004 
HILL, J.R. et al. Exploring research on internet-based learning: from infrastructure to interactions. In: JONASSEN, D.H. (Ed.). Handbook of research on educational communications and technology, New York: Macmillan, 2003. p.433-60.

HOLMES, G.; ABINGTON-COOPER, M. Pedagogy vs. andragogy: a false dichotomy? Journal of Technology Studies, v.26, n 2, p.50-55, 2000.

HUGHES, G.; LEWIS, L. Who are successful online learners: exploring the relationships betwen learner identities and their new experiences of online pedagogies and technologies. Essex: University of East London, 2002. 21 p.

ILLERA, J.L.R. Como as comunidades virtuais de prática e de aprendizagem podem transformar a nossa concepção de educação. Sísifo: Revista de ciência da educação, v.3, p.117124, 2007.

IMEL, S. Learning technologies in adult education: myths and realities. Educational Resources Information Center, n. 17, 2001.

JONES, M.G.; BRADER-ARAJE, L. The impact of constructivism on education: language, discourse, and meaning. American Communication Journal, v.5, n.3, 2002. Disponível em: <http://www.acjournal.org/ holdings/vol5/iss3/ special/jones.htm>. Acesso em: 2 dez. 2005.

KING, F.B. A virtual student: not a ordinary Joe. Internet and Higher education, v.5, p.157-166, 2002.

LAGUARDIA, J. Avaliação em ambientes virtuais de aprendizagem. Educação \& Pesquisa, v.33, n.3, p.513-530, 2007.

LAGUARDIA, J.; CASANOVA, A.; MACHADO, R.R. A experiência de aprendizagem on-line em um curso de qualificação profissional em saúde. Trabalho Educação e Saúde, v.8 n. 1 , p.97-122, 2010.

LAGUARDIA, J.; MACHADO, R.R.; COUTINHO, E. Interação nos ambientes virtuais de aprendizagem: análise de dois fóruns de discussão. RECIIS: Revista eletrônica de comunicação informação inovação em saúde, v.3, n.2, p.37-40, 2009.

LAURILLARD, D. Rethinking teaching for the learning society. EDUCAUSE Review, v.37, n. 1, p. 16-25, 2002.

LEFOE, G. Creating constructivist learning environments on the web: the challenge in higher education. ASCILITE CONFERENCE, 1998, Wollongong. Proceedings... Australia: [s.n.]., 1998. p.453-464.
LIANG, X:; CREASY, K. Classroom assessment in web-based instructional environment: instructors' experience. Practical Assessment Research \& Evaluation, v.9, n.7, p.1-7 2004

LÖEFSTED, J.J. et al. Virtualization of higher education in the era of globalization: issues and trends. Stockholm: Institute of International Education Stockholm University, 2001. 101p.

LOSSO, A.R.S. Reflexões sobre a educação a distância: o papel do professor tutor na perspectiva da mediação pedagógica. Linhas, v.3, n.2, p.131-146, 2002.

MA, L.; VOGEL, D.; WAGNER, C. Will virtual education initiatives succeed? Information Technology and Management, n.1, p.209-227, 2000.

MAUDSLEY, G. Roles and responsabilities of the problem based learning tutor in the undergraduate medical curriculum. British Medical Journal, v 318, p.657-661, 1999.

McKIMM, J.; JOLLIE, C.; CANTILLON, P. ABC of learning and teaching: web based learning. British Medical Journal, v.326, p.870-873, 2003

MISANCHUK, M.; ANDERSON, T. Building community in an online learning environment: communication, cooperation and collaboration. In: ANNUAL MID-SOUTH INSTRUCTIONAL TECHNOLOGY CONFERENCE, 6., 2001, Murfreesboro. Proceedings... Murfreesboro: [s.n.], 2001, p.8-10.

NICHOLS, M. A theory for elearning. Educational Technology \& Society, v.6, n.2, p.1-10, 2003

NULDEN, U. E-ducation: research and practice. Journal of Computer Assisted Learning, v. 17, p.363-375. 2001

OLIVER, M. et al. Multiple perspective and theoretical dialogue in learning technology. In: ASCILITE CONFERENCE, 2002, Auckland. Proceedings... Auckland: ASCILITE, 2002. p.1-9. PERAYA, D. O ciberespaço: um dispositivo de comunicação e de formação midiatizada. In: ALAVA, S. et al. Ciberespaço e formações abertas: rumo a novas práticas educacionais. Porto Alegre: Artmed, 2002. p.25-52.

PRIMO, A. Enfoques e desfoques no estudo da interação mediada por computador. 2005. Disponível em: http:// www6.ufrgs.br/limc/pesquisa.html.

PETERS, O. A educação a distância em transição. São Leopoldo: Unisinos, 2004.

PIAGET, J. A epistemologia genética. Petrópolis: Vozes, 1971. 
QUINTANA, Y. Evaluating the value and effectiveness of internet-based learning. ANNUAL CONFERENCE OF THE INTERNET SOCIETY, 6., 1996, Montreal. Reston: The Internet Society. 1996.

RACHAL, J. R. Andragogy's detectives: a critique of the present and a proposal for the future. Adult Education Quaterly, v.52, n.3, p.210-227, 2002.

SAINT CLAIR, R. Andragogy revisited: theory for the $21^{\text {st }}$ century. Educational Resources Information Center, n.19, 2002.

STRUCHINER, M.; GIANNELLA, T.R. Formação de profissionais de saúde e educação à distância: elementos fundamentais. Disponível em: <http://www.observatorio.nesc.ufrn.br/ texto_forma 15.pdf >. Acesso em: 6 dez. 2010.

STRUCHINER, M.; GIANNELLA, T.R. Novas tecnologias de informação e comunicação na formação de recursos humanos em saúde. In: MONTEIRO, S.; VARGAS, E. (Orgs.). Educação, comunicação e tecnologia educacional: interfaces com o campo da saúde. Rio de Janeiro: Fiocruz, 2006. p.129-140.
TESTA, M.G. Algumas reflexões críticas sobre a educação a distância. In: MISOCZKY, M.C.A.; CARVALHO, N.M.; OLIVO, V. (Orgs.). Educação a distância: reflexões críticas e experiências em saúde. Porto Alegre: Dacasa, 2001. p.7-18.

TIMMS, D. et al. Review of telematics based open and distance learning. Luxembourg and Brussels: Centre for Research and Development in Learning Technology, 1999.

VALCKE, M.M.; LEEUW, F.L. Evaluating digital distance learning programs and activities. Washington: World Bank Institute, 2004

VIGOTSKI, L.S. A formação social da mente. São Paulo: Martins Fontes, 2007.

VRASIDAS, C. Constructivism versus objectivism: implications for interaction, course design, and evaluation in distance education. International Journal of Educational Telecommunications, v.6, n.4, p.339-362, 2000.

WENGER, E. Communities of practice: learning, meaning, and identity. New York: Cambridge University Press, 1998. 